\title{
Sincretismo cristiano-judío en las creencias y prácticas religiosas de los judeoconversos castellanos en el tránsito de la Edad Media a la Moderna
}

\section{Christian-Jewish Syncretism in the Religious Beliefs and Practices of Castilian Conversos in the Transition from the Medieval to the Modern Age}

\author{
Enrique Cantera Montenegro \\ Universidad Nacional de Educación a Distancia \\ ecantera@geo.uned.es
}

Fecha de recepción: 19-10-2018

Fecha de aceptación: 17-12-2018

\section{RESUMEN}

El objetivo principal de este trabajo consiste en sacar a la luz elementos que permitan confirmar un sincretismo cristiano-judío inconsciente, no voluntario, en las creencias y prácticas religiosas de los judeoconversos castellanos en el momento de tránsito de la Edad Media a la Moderna. El trabajo se sustenta en la consulta y análisis de numerosos procesos inquisitoriales incoados a judeoconversos castellanos a fines del siglo XV y comienzos del XVI, así como en otra diversa documentación inquisitorial. A través de las fuentes estudiadas es posible detectar rasgos que evidencian una progresiva confusión entre creencias, expresiones y manifestaciones religiosas cristianas y judías, como expresión más patente de que las transferencias religiosas y la aculturación era una realidad a la que en ese tiempo estaban sujetos los conversos, incluso quienes, como los criptojudíos, se aferraban al judaísmo y manifestaban un firme convencimiento en la superioridad de la religión judía sobre la cristiana. La conclusión principal es que esta situación era el reflejo de una realidad en la que, rotas las conexiones con el judaísmo oficial, la "religión" de los criptojudíos se diluía paulatina y progresivamente en el seno del cristianismo.

PALABRAS CLAVE: Judeoconversos, Castilla, fines del siglo XV y comienzos del XVI, sincretismo religioso, procesos inquisitoriales.

\section{ABSTRACT}

The main objective of this study is to identify certain elements that may confirm an unconscious Christian-Jewish syncretism in the religious beliefs and practices of Castilian Conversos in the transition from the Medieval to the Modern Age. The research is based on consultation and analysis of numerous inquisitorial trials of Castilian Conversos at the end Inquisitorial records. The selected sources allow us to discern certain traits that point to a progressive confusion between Christian 
and Jewish religious beliefs, expressions and manifestations. This is a clear indication that religious transfer and acculturation constituted a reality to which Conversos were exposed. This was the case even among those who, like Crypto-Jews, clung on to Judaism and expressed a firm conviction of the superiority of the Jewish over the Christian religion. The main conclusion is that, once the connections with official Judaism were broken, the religion of the Crypto-Jews slowly but progressively dissolved into the mainstream of Christianity.

KEY WORDS: Conversos, Castile, End of the Fifteenth and Early Sixteenth Centuries, Religious Syncretism, Inquisitorial Trials.

\section{INTRODUCCIÓN}

En los últimos decenios las investigaciones acerca de las creencias y las expresiones religiosas de los judeoconversos han conocido un notable desarrollo. Haciendo uso como fuente principal de información de documentación inquisitorial, diversos autores han profundizado en el estudio del nivel de conocimiento y de práctica religiosa que los conversos tenían del cristianismo, por una parte, así como de las creencias y práctica secreta de la religión judía, por la otra ${ }^{1}$. Pero en el amplio colectivo de los conversos se manifestaban diversas actitudes en relación con la práctica religiosa; para el momento de tránsito de la Edad Media a la Moderna, María del Pilar Rábade identifica hasta cinco tipos de posicionamientos diferentes: a) Los criptojudíos, que permanecían firmemente aferrados a la religión mosaica; b) los escépticos, que mostraban idéntico desapego y escepticismo hacia cristianismo y judaísmo; c) los dubitativos, que manifestaban unas profundas dudas acerca de en cuál de las dos religiones se hallaba la verdad, por lo que profesaban una especie de religión híbrida, a medio camino entre el cristianismo y el judaísmo; d) los sincréticos, que practicaban de forma convencida una religión, fuera la cristiana o la judía, pero cuyas creencias y prácticas estaban contaminadas, de forma inconsciente, por elementos que eran propios de la otra religión; y e) los cristianos sinceros, que habían abrazado el cristianismo de forma absolutamente convencida, y que se esforzaban por cumplir de la forma más exacta posible con su nueva religión².

El objetivo principal de este trabajo consiste en tratar de detectar elementos que evidencien un sincretismo inconsciente en las creencias y las prácticas religiosas de los judeoconversos castellanos a fines del siglo XV y principios del XVI. Como señala María del Pilar Rábade, los rasgos de sincretismo inconsciente entre las dos religiones no son fáciles de detectar en la documentación inquisitorial ${ }^{3}$. Y así es, porque si en su pliego de cargos el procurador fiscal exponía de forma pormenorizada los ritos de la religión judía

1 Entre la abundante bibliografía relativa a estas cuestiones cabe destacar el estudio de $\mathrm{H}$. Beinart, Los conversos ante el tribunal de la Inquisición, Barcelona, Riopiedras Ediciones, 1983; los diversos y fundamentales trabajos de M. P. Rábade Obradó, entre ellos los titulados "Expresiones de la religiosidad cristiana en los procesos contra los judaizantes del tribunal de Ciudad Real/Toledo, 1483-1507", En la España Medieval, 13 (1990), pp. 303-330, "Religiosidad y práctica religiosa entre los conversos castellanos (1483-1507)", Boletín de la Real Academia de la Historia, tomo CXCIV, Cuaderno I (Enero-Abril, 1997), pp. 83-141, y "La instrucción cristiana de los conversos en la Castilla del siglo XV", En la España Medieval, 22 (1999), pp. 369-393; o el completísimo análisis de D.M. Gitlitz, Secreto y engaño. La religión de los criptojudíos, Salamanca, Junta de Castilla y León, 2003.

2 M. P. Rábade Obradó, “Expresiones de la religiosidad cristiana”, pp. 307-313.

3 Ibídem, p. 312. 
que eran guardados por el acusado, el abogado refería también de forma minuciosa en su pliego de descargos las prácticas de la religiosidad cristiana de su defendido; pero unas y otras se presentan como prácticas "puras", es decir no contaminadas por la otra religión. De este modo, para la detección de elementos de sincretismo inconsciente resulta obligada una lectura detenida de numerosos procesos inquisitoriales, tratando de vislumbrar en las declaraciones del acusado y de los testigos del fiscal y de la defensa testimonios que evidencien una confusión entre creencias y expresiones de las dos religiones ${ }^{4}$. Aunque pudiera suponerse que las manifestaciones de sincretismo se darían principalmente en los grupos de dubitativos, tendremos ocasión de comprobar que afloran también con mucha frecuencia entre los criptojudíos, como expresión más patente de que las transferencias religiosas y la aculturación era una realidad a la que estaban sujetos todos los conversos, incluso quienes se aferraban al judaísmo y manifestaban un firme convencimiento en la superioridad de la religión judía sobre la cristiana.

Entre las causas que pueden explicar este sincretismo inconsciente de los conversos ocupa un destacado lugar la escasa instrucción que recibieron en la religión cristiana, lo que motivó que sus conocimientos de ella fueran muy rudimentarios, favoreciendo la confusión doctrinal y la mezcla de prácticas ${ }^{5}$. Del mismo modo, la expulsión de 1492 provocó el aislamiento progresivo de los criptojudíos respecto del judaísmo, quedando inmersos en un universo de creencias cristianas, lo que sería causa de cambios significativos en los principios fundamentales de $\mathrm{su} \mathrm{fe}^{6}$. Si hasta la salida de los judíos de los reinos hispanos era habitual que los judaizantes contaran con el asesoramiento de algún rabí, quien les resolvía las dudas que se les planteaban en materia religiosa, después de 1492 los criptojudíos quedaron en cierto modo desamparados, de forma que ya no podían acudir para resolver sus dudas sino a algún converso más versado en la religión mosaica. Por todo ello, apenas transcurrida una generación desde la expulsión, el judaísmo practicado por los criptojudíos ya no era plenamente ortodoxo, y sus ritos y prácticas judías se entremezclaban con otras que eran propias del cristianismo.

\section{LA PROGRESIVA APROXIMACIÓN DE LAS CREENCIAS RELIGIOSAS DE LOS CRIPTOJUDÍOS AL SISTEMA DE CREENCIAS CRISTIANO}

Aunque el sincretismo cristiano-judío ha dejado sus huellas, principalmente, en las expresiones más externas de la religiosidad de los conversos, es decir en los ritos, ceremonias y oraciones, no hay duda de que también se dejó sentir en el más complejo sistema de creencias. Veamos algunos ejemplos de ello.

\footnotetext{
4 Además de documentación consultada en la sección de Inquisición de Toledo (en adelante, IT) del Archivo Histórico Nacional (en adelante, AHN), he revisado principalmente las siguientes colecciones documentales: $\mathrm{H}$. Beinart, Records of the Trials of the Spanish Inquisition in Ciudad Real (en adelante, Records), Jerusalem, The Israel National Academy of Sciences and Humanities, 1974-1985, 4 vols.; C. Carrete Parrondo, Fontes Iudaeorum Regni Castellae. II. El Tribunal de la Inquisición en el Obispado de Soria (1486-1502), Salamanca, Universidad Pontificia de Salamanca-Universidad de Granada, 1985; C. Carrete Parrondo, Fontes iudaeorum Regni Castellae III. Proceso inquisitorial contra los Arias Dávila segovianos: un enfrentamiento social entre judíos y conversos, Salamanca, Universidad Pontificia de Salamanca-Universidad de Granada, 1986; C. Carrete Parrondo y C. Fraile Conde, Fontes Iudaeorum Regni Castellae IV. Los judeoconversos de Almazán. 1501-1505. Origen familiar de los Laínez, Salamanca, Universidad Pontificia de Salamanca-Universidad de Granada, 1987; y R. Gracia Boix, Colección de documentos para la historia de la Inquisición de Córdoba, Córdoba, Publicaciones del Monte de Piedad y Caja de Ahorros de Córdoba, 1982.

5 M. P. Rábade Obradó, "La instrucción cristiana de los conversos”, pp. 369 y 380.

6 D. M. Gitlitz, Secreto y engaño, p. 109.
} 
El judaísmo y el cristianismo difieren considerablemente en su concepción de la vida ultraterrena y de la trascendencia del alma. La creencia en una vida después de la muerte tomó cuerpo muy lentamente en el judaísmo primitivo, pero llegó a ser una auténtica convicción de fe en el período talmúdico (siglos II a VI d. C.), sustentada en la esperanza en una resurrección del cuerpo al final de los tiempos y en la creencia en un alma que trasciende la muerte física? ${ }^{7}$. En la Edad Media, pese a que era habitual que los judíos afirmaran su confianza en la resurrección de los justos tras la venida del Mesías, siguió siendo ajeno al judaísmo el concepto de salvación individual del alma, lo mismo que la concepción del cielo como un espacio en el que las almas vivirían por toda la eternidad. Estas son concepciones más propias del cristianismo, en el que se impuso la idea de que, de forma previa al Juicio Final universal, habría un juicio particular para cada persona, inmediatamente después de la muerte. La idea de salvación individual y de juicio particular motivó el desarrollo del género del ars moriendi, con el propósito de ayudar a los fieles a preparar adecuadamente el tránsito a la eternidad.

Por lo que respecta a los criptojudíos, desde muy pronto asimilaron la idea cristiana de la salvación individual del alma, pese a que afirmaran que solo era posible alcanzarla a través de la Ley de Moisés. Para David M. Gitlitz, la confusión entre la noción judía de la justificación por la obediencia a la Ley y la idea cristiana de la salvación por la fe es la expresión más evidente de sincretismo en el sistema de creencias de los criptojudíos ${ }^{8}$. Pero se trata de un proceso inconsciente, de algo que trascendió desde el cristianismo al pensamiento religioso de los criptojudíos pese a su rechazo de la escatología y la cosmografía cristianas, lo que se expresa en sus frecuentes dudas acerca de la existencia del infierno y del purgatorio.

El término Purgatorio nació en el cristianismo a fines del siglo XII y se difundió de forma lenta, estrechamente vinculado a la idea de salvación individual ${ }^{9}$. Pese a que el concepto de Purgatorio no existe en el judaísmo, trascendió al sistema de creencias de los criptojudíos, de forma que no es raro encontrar referencias a él en documentación inquisitorial relacionada con judaizantes. Así, en el proceso incoado en los años 1500 a 1505 contra Mari Álvarez, vecina de La Puebla de Alcocer (Badajoz), se recoge un testimonio acerca de las experiencias místicas de Inés Esteban, la "moza de Herrera", quien afirmaba "que venía un ángel a ella, e que primero avía venido su madre, que era muerta, e que le pareçía que la llevaba el ángel a Purgatorio, e que veýa allí muchos muertos e las penas que padecían ${ }^{10}$.

Otras manifestaciones de sincretismo en el sistema de creencias de los criptojudíos pueden rastrearse en la concepción mesiánica. La idea mesiánica, entendida como la esperanza en la aparición escatológica de un líder carismático, del linaje de David, que propiciaría la salvación definitiva de Israel, surgió en el judaísmo postbíblico con un carácter eminentemente político-nacional: al final de los tiempos, el Mesías-rey destruiría a los enemigos de Israel, reconstruiría el Templo e instauraría un reino de paz. Más tarde, la concepción del Mesías como rey se completó con su función de sacerdote: además de la liberación política de Israel, el Mesías favorecería la redención religiosa y espiritual, destruyendo el pecado e instaurando el reino de Dios en el mundo ${ }^{11}$. Pero, en tanto que la

7 J. Maier y P. Schäfer, Diccionario del judaísmo, Estella, Editorial Verbo Divino, 1996, p. 409, entrada "Vida después de la muerte".

8 D. M. Gitlitz, Secreto y engaño, p. 122.

9 J. Le Goff, La naissance du Purgatoire, Paris, Gallimard, 1981.

10 AHN, IT, leg. 134, no 7, fol. 6v.

11 J. Trebolle Barrera, "Apocalipticismo y mesianismo en el mundo judío", en J. Mangas y S. Montero (Coords.), El Milenarismo. La percepción del tiempo en las culturas antiguas, Madrid, Editorial Complutense, 2001, p. 73. 
redención mesiánica tiene en el judaísmo un carácter propiamente público y acontece en el marco de la comunidad, para el cristianismo se inscribe en la esfera individual y se refleja en el alma de cada persona ${ }^{12}$. Del mismo modo, la intervención del Mesías en la redención individual de las personas es mucho más limitada en el judaísmo que en el cristianismo; así, en tanto que para el judaísmo la salvación obedece más al cumplimiento de la Ley que a una mediación del Mesías, en el cristianismo requiere siempre de la mediación mesiánica ${ }^{13}$. Después de 1492 numerosos criptojudíos asimilaron la concepción mesiánica del cristianismo, de forma que a la idea propiamente judía de un Mesías liberador político de la comunidad y favorecedor de la restauración de un Reino judío, unieron la idea cristiana del Mesías como liberador de las almas. En su confusión de ideas, si algunos identificaban al Mesías con Moisés, otros veían en él al Anticristo, y expresaban su confianza en que destruiría a la Iglesia y aniquilaría a los cristianos.

Asimismo, trascendió lentamente desde el cristianismo al sistema de creencias de los criptojudíos la noción de unas figuras que podían actuar como mediadores de los hombres ante la divinidad, al estilo de los santos cristianos, algo absolutamente ajeno al judaísmo; se trata siempre de personajes bíblicos de especial significación en la historia salvífica de Israel, como Moisés y Esther, principalmente. Aunque el pleno desarrollo de esta noción es posterior en el tiempo, de forma que no fue sino en la segunda mitad del siglo XVI cuando los criptojudíos hicieron de la figura de Moisés el equivalente a un santo cristiano, es muy probable que las primeras expresiones sean ya de fines del siglo XV. Una prefiguración de Moisés como santo protector de los judíos y de los conversos es la que se contiene en la declaración que el día 3 de diciembre de 1500 hizo ante el tribunal de la Inquisición Leonor de la Fuente, vecina de Herrera del Duque, en el proceso que fue incoado en los años 1500 a 1502 contra diversos judeoconversos vecinos de Herrera del Duque y de La Puebla de Alcocer. En su comparecencia ante los inquisidores, Leonor de la Fuente "dixo que ogaño, por la Quaresma pasada, oyó decir a Beatriz, fija de Luys Alfonso, carniçero, que avía visto a Moysén en su casa, con mucho resplandor ${ }^{14 " . ~}$

Esta imagen de Moisés resplandeciente puede tener origen bíblico, pero puede también guardar algún tipo de relación con la transfiguración de Jesús, Moisés y Elías en el monte Tabor narrada en los Evangelios:

Y seis días después toma Jesús consigo a Pedro, a Santiago y a Juan, su hermano, y sube con ellos a un monte elevado a solas. Y se transfiguró en presencia de ellos, y comenzó a relumbrar su faz como el sol, y sus vestiduras se pararon blancas como la luz. Y de pronto aparecieron a su vista Moisés y Elías conversando con él ${ }^{15}$.

A fines del siglo XV hay también alguna referencia documental a la identificación entre Moisés y Jesús por parte de algún converso. Es el caso de una mujer anónima, vecina de Aranda de Duero, a quien un joven, estando en la iglesia, había oído cómo "al tiempo que alçavan la hostia dezía 'Señor Moysén, en ty adoro'16”.

12 G. Scholem, The Messianic Idea in Judaism, New York, Schockem, 1971, p. 1.

13 D. M. Gitlitz, Secreto y engaño, p. 117.

14 AHN, IT, leg. 137, nº 9, fol. 2r.

15 "Evangelio de San Mateo", 17, 1-3, en Sagrada Biblia. Versión crítica sobre los textos hebreo y griego por José María Bover, S.I., y Francisco Cantera Burgos, Madrid, Biblioteca de Autores Cristianos, 1961 (6ª ed.), p. 1.167.

16 Archivo General de Simancas (en adelante, AGS), Patronato Real, Inquisición, leg. 28/73, fol. 1.114r. C. Carrete Parrondo, Fontes Iudaeorum Regni Castellae (en adelante, FIRC), II. El Tribunal de la Inquisición en el 


\section{RASGOS DE SINCRETISMO EN GESTOS, ACTITUDES Y COMPORTAMIENTOS DE LOS JUDEOCONVERSOS}

Con frecuencia, el sincretismo cristiano-judío se manifestaba en gestos y actitudes de los conversos al rezar las oraciones judías en la sinagoga o en la casa, o al asistir a misa en la iglesia. Una prueba evidente de este sincretismo es la que presenta a los criptojudíos rezando arrodillados, algo que no era propio del judaísmo medieval, aunque sí del cristianismo.

En el judaísmo primitivo era habitual orar de rodillas o postrados, en señal de sumisión a Dios. Pero desde los tiempos talmúdicos, y a lo largo de toda la Edad Media, los judíos oraban sentados o de pie, lo que es muy posible que fuera impuesto por los rabinos por el deseo de diferenciarse de los cristianos, ya que la oración de rodillas se asociaba al ritual cristiano.

Desconocedores de la tradición rabínica, e influidos por los modelos cristianos de reverencia, no era raro que los criptojudíos rezaran arrodillados. Los ejemplos son numerosos; así, en el proceso inquisitorial promovido en 1483-1484 contra Sancho de Ciudad y su mujer Mari Díaz, judeoconversos vecinos de Ciudad Real, testificó Juana, quien declaró

que avrá veynte e seis años que moró este testigo con la de Juan de Çibdad, e que moró con ella doze años, e que ha que salió de su casa catorze, e que sabe que guardava la Ley de Muysén, guardando los sábados e pascua de la Ley de los judíos e faziendo todas sus çerimonias. E que en ella no avía señal de christiana. E que la dicha su ama e Çeçilia González e la çerera vieja dezían a este testigo que yvan a misa, e yvan a casa de Sancho de Çibdad, donde este testigo las vido rezar de rodillas e cubiertas las cabeças e sabadeando ${ }^{17}$. E que esto es lo que sabe e vido para el juramento que fizo ${ }^{18}$.

Este mismo gesto de rezar arrodillados se documenta también en el proceso inquisitorial incoado al mercader cordobés Juan de Córdoba Membreque en los años 1502 a 1504; en él se hace un amplio relato de las predicaciones de carácter profético y mesiánico que su sobrino, el bachiller Alonso de Córdoba, pronunciaba todos los lunes y jueves ante un centenar de judeoconversos ${ }^{19}$. En las declaraciones de los testigos se describen las prácticas rituales que tenían lugar con ocasión de estas reuniones, como una especie de parodia de la misa, que iba seguida de unas procesiones de hombres y mujeres vestidos de blanco, descalzos y con velas encendidas, con el fin de suplicar el perdón divino y rogar a Dios que los trasladara a tierras de promisión. Uno de los testigos las relata así:

Et después de todo esto, el dicho rabý predicador se abaxó de dicho predicatorio, et el dicho Johan de Córdova et los otros que allí estaban, besaron la mano al dicho rabý, et él les dio su bendiçión, poniéndoles la mano sobre las cabeças, sin los santiguar. Et después,

Obispado de Soria (1486-1502), Salamanca. Universidad Pontificia de Salamanca - Universidad de Granada, 1985, p. 174, parágrafo 425.

17 El vocablo sabadear hace referencia a la acción de rezar acompañada de los gestos típicamente judíos de alzar y bajar la cabeza y mover rítmicamente el cuerpo.

18 AHN, IT, leg. 139, n 11, fol. 12v. H. Beinart, Records, I, p. 26.

19 El proceso inquisitorial incoado a Juan de Córdoba es transcrito íntegramente por R. Gracia Boix, Colección de documentos para la historia de la Inquisición de Córdoba, doc. V, pp. 31-79. El movimiento profético cordobés fue estudiado por H. Beinart, "A Prophesyng Movement in Cordova in 1499-1502" (en hebreo), en I.F. Baer Memorial Volume, Zion, 44 (1979), pp. 190-200, a través de una relación del tribunal de la Inquisición de Córdoba que se conserva en el AGS, Estado, leg. 1, 2 ${ }^{\circ}$ fols. 392-393. 
el dicho Johan de Córdova anduvo en proçisyón con todos los otros que estaban en la dicha synoga e ayuntamiento, tras el dicho rabý predicador. Asymismo, el dicho Johan de Córdova estubo en çierto abto quel dicho rabý fazía en contra fazen la misa, puesto en un altar, vestido de blanco, segund que de suso está dicho, y en lugar de la ostia alçaba el dicho rabý predicador un libro judaico abierto, y en lugar del cáliz otro libro judaico menor, et se herían el dicho Johan de Córdova y los otros que allí estaban en los pechos, segund que los christianos lo fazen al tiempo que alçan el Corpus Christo. Et después de acabada la misa, el dicho rabý les echava la vendiçión syn los santiguar ${ }^{20}$.

Durante las predicaciones, los asistentes permanecían de rodillas, en actitud de profundo recogimiento:

[...] e que vio cómo entre tanto quel dicho bachiller Menbreque estaba predicando, el dicho Juan de Córdova Menbreque y todas las otras personas que allí estaban, y este testigo juntamente con ellos, tenían cada uno en su mano una candela de çera blanca ençendidas, y todos estaban hincados de rodillas, y este testigo asymismo ${ }^{21}$.

Otras posibles muestras de sincretismo pueden encontrarse en algunas actitudes de los conversos mientras asistían a misa; entonces, sus convecinos cristianos viejos observaban con atención todos sus gestos y actitudes, por si pudieran detectar indicios de descreimiento o de falta de respeto. Y ponían especial cuidado en el momento de la consagración, como se expresa en la declaración que el día 27 de julio de 1490 hizo ante los inquisidores de la diócesis de Osma fray Juan de Vitoria, comendador de la Orden de la Merced de Santa Olalla de Soria, quien afirmó que Gonzalo Sánchez Caballero, un cristiano nuevo vecino de Soria, tenía fama de mal cristiano,

e que oyó dezir este testigo después dende a çiertos días a... Juan de Nunçibar que sobre aviso avía mirado a... Gonçalo Sánchez Cavallero, e que vio que un día entró en una iglesia e que non se santiguó, e que al tiempo que alçaron que vio que... Gonçalo Sánchez Cavallero que baxó los ojos al suelo, e que nunca miró el Corpus Christi. E que a esta cabsa, estando este testigo un día en misa, en Sant Françisco, que estaba junto con... Gonçalo Sánchez Cavallero, e que al tienpo que alçaron a Nuestro Señor, sobre este aviso miró este testigo a... Gonçalo Sánchez Cavallero, e vio este testigo que mientras alçaron a Dios siempre tovo los ojos baxos mirando al suelo e nunca miró a Dios. E dixo este testigo que... Gonçalo Sánchez Cavallero que tiene mucha fama pública en... Soria que es judío puro ${ }^{22}$.

Estaba bastante extendida la suposición de que los judeoconversos no miraban hacia el altar en el momento de la consagración por desprecio hacia la Eucaristía, lo que se interpretaba como una prueba inequívoca de increencia en un principio fundamental en la doctrina católica como es el de la transubstanciación ${ }^{23}$. Pero, en mi opinión, cabe otra posible interpretación. Así, es bien conocido el sentimiento de profundo respeto, e incluso de temor reverencial, que inspira Dios en el judaísmo, de forma que no puede ser representado con

20 AHN, Inquisición, leg. 4.724, doc. 2, fol. 5v. R. Gracia Boix, Colección de documentos para la historia de la Inquisición de Córdoba, doc. V, pp. 36-37.

21 Ibídem, fol. 11r-v, p. 43.

22 AGS, Patronato Real, Inq., leg. 28/73, fol. 959 v. C. Carrete Parrondo, FIRC, II. Inquisición de Soria, pp. 34-35, parágrafo 41.

23 EI IV Concilio de Letrán (1215) había consagrado definitivamente el término "transubstanciar" para referirse a la Eucaristía, contribuyendo a reforzar una creencia indubitable desde tiempos de los Padres de la Iglesia: la conversión de la hostia en el cuerpo de Cristo y del vino en su sangre en el momento de la consagración. 
figura humana ${ }^{24}$ y su nombre sagrado solo es pronunciado en determinadas ceremonias de culto $^{25}$. Es muy posible que los judeoconversos, imbuidos de este sentimiento de profundo respeto hacia Dios, no se atrevieran a mirar directamente hacia la hostia y el cáliz cuando eran alzados, y bajaran respetuosa y temerosamente la mirada. No hay que perder de vista que esta actitud era también obligada por el ritual de la iglesia oriental y por el antiguo rito de las iglesias occidentales, por ejemplo por el visigótico-mozárabe, en los que está terminantemente prohibido que los fieles miren directamente la hostia y el cáliz durante la consagración; es por este motivo por el que en las iglesias orientales se difundió el uso del iconostasio (eikonostasion), una estructura en la que se colocan los iconos y que sirve de separación entre el altar y el presbiterio respecto de la nave, impidiendo que los fieles presencien la consagración; y algo parecido sucedía en las iglesias prerrománicas hispanas, en las que el altar suele estar dispuesto de tal modo que quede reservado de las miradas de los fieles durante la consagración. Será con el rito romano, que a lo largo de los siglos X y XI se impuso de forma definitiva en todo el Occidente europeo, cuando la consagración pasa a ser algo público y visible para los fieles, quienes desde entonces se afanan por ver la hostia consagrada ${ }^{26}$.

\section{LA ACENTUADA AMBIVALENCIA DE LOS SINCRÉTICOS}

Son muy frecuentes en los procesos inquisitoriales declaraciones de testigos del fiscal en las que se pone de manifiesto que los acusados llevaban una doble vida, como judíos y como cristianos. Es el caso de Sancho de Ciudad, vecino de Ciudad Real, de quien Rodrigo de los Olivos afirmaba que "es público e notorio en esta çibdad que el dicho Sancho de Çibdad ha vevido más en vida de judío que non de christiano27", o el de Marina Gentil, vecina de la misma ciudad, de quien Catalina González "sabe e vido en aquel tiempo que holgava algunos sábados, e que algunos viernes ençendía los candiles linpios, e non le vido más, porque más tiraba a christiana que non ha confesa ${ }^{28 " .}$.

Algunos judeoconversos trataban de cumplir con los preceptos de las dos religiones, y justificaban su actitud en la identidad entre ambas. Hablando sobre la misa, Diego López, un cristiano nuevo que residía en Berlanga de Duero, afirmaba

que quanto se dize en la misa son los salmos que los judíos dizían en la oración, e la epístola es lo de las profecías que leýan los judíos, e el Ebangelio hera del Génesi, e todo es cosa de la ley vieja, e todo es bueno, e no hallo otra duda ni cosa que no entyenda, salvando el ademán que fazen quando alçan, que dizen que ven allí a Dios; aquello yo no lo puedo creer al mundo, ni sé por dónde lo pueden probar ellos, que aquello no está nada dello en la ley vieja ${ }^{29}$.

24 En los códices y manuscritos hebreos iluminados de época medieval, Yahvé suele ser representado mediante una zarza ardiendo, un haz de rayos luminosos o una mano que baja del cielo (es la hamsa o mano de Dios).

25 La pronunciación del nombre sagrado de Yahvé está estrictamente limitada en el judaísmo, ya desde tiempos remotos, por lo que la referencia a Dios se hace de forma habitual con el término Adonay (= Señor, mi Señor), en tanto que el Tetragrama, es decir la palabra formada por las cuatro letras (YHWH) que componen el nombre sagrado de Yahvé, es impronunciable, salvo en ciertas ceremonias religiosas especialmente solemnes.

26 M. Garrido Bonaño, Curso de Liturgia Romana, Madrid, Biblioteca de Autores Cristianos, 1961, pp. 269-291.

27 AHN, IT, leg. 139, no 11, fol. 10v. H. Beinart, Records, I, p. 21.

28 AHN, IT, leg. 150, nº 6, fol. 3r. H. Beinart, Records, I, pp. 534-535.

29 AGS, Patronato Real, Inq., leg. 28/73, fol. 1.001r. C. Carrete Parrondo, FIRC, II. Inquisición de Soria, p. 71, parágrafo 132 . 
Existen diversos ejemplos del propósito de numerosos conversos de cumplir con los dos credos. Es particularmente significativo a este respecto el hecho de que bastantes de ellos celebraran los bautizos de sus hijos en sábado en lugar de hacerlo en domingo, como entonces era más frecuente, lo que como reconocían obedecía a una decidida voluntad de solemnizar el sábado. De este modo, cumplían con un precepto cristiano, el sacramento del bautismo, asociándolo al día sagrado del judaísmo. En el proceso promovido contra Leonor Álvarez, mujer de Fernando Álvarez, vecinos de Ciudad Real, se incluye una confesión de Juana Rodríguez, mujer del arrendador Alonso Álvarez, hecha el día 14 de agosto de 1512, en la que se dice "que este confesante bautizó a un fijo suyo, que se llama Juanico, que a dos años, e le fizo bautizar en sábado, e que este confesante holgó el dicho día de sábado, e que ovo placer de le bautizar en sábado por la afición que este confesante tenía a la guarda del sábado $30 "$.

Al mismo propósito de honrar tanto el sábado como el domingo parece obedecer el hecho de que algunos judeoconversos vistieran ropa de fiesta ambos días de la semana. En su declaración en el proceso inquisitorial incoado a Juan de la Sierra, mercader vecino de Ciudad Real, Juana González afirmó el 8 de mayo de 1511 que había servido en casa del acusado por espacio de medio año, y

que se acuerda que vido a las dichas su ama e hija Leonor que los sábados se vestían de buenas ropas, e que aquellas mismas les veýa este testigo traer en los días de domingos, et luego el lunes adelante se vestían de otras ropas que no heran de fiesta, las quales traýan toda la semana hasta el sábado, luego se vestían de aquellas buenas ropas e las traýan el domingo, como dicho es. E que lo mismo hazía la hermana de la mujer del dicho Juan de la Sierra, que morava dentro en su casa ${ }^{31}$.

Cabe la posibilidad de que las conversas citadas vistieran las ropas de fiesta del sábado asimismo durante el domingo para no llamar la atención, pero es posible también que esta forma de actuar obedezca al deseo de solemnizar ambos días, en lo que sería una muestra de ambivalencia religiosa.

Son muy interesantes también las referencias que se contienen en algunos procesos inquisitoriales a la recitación por parte de algunos criptojudíos de los llamados siete salmos penitenciales o salmos de confesión, como se denomina en la Iglesia cristiana a los salmos 6 , 31, 37, 50, 101, 129 y 142, según la numeración de la Septuaginta y de la Vulgata ${ }^{32}$. Se trata de los salmos en los que el rey David expresa arrepentimiento por sus pecados y su firme propósito de enmienda, alternando con súplicas a la misericordia divina. La denominación de "salmos penitenciales" no es bíblica, sino cristiana, pues así son denominados en el primitivo cristianismo al menos desde tiempos de san Agustín. A comienzos del siglo XIII, el papa Inocencio III ordenó su rezo en las iglesias durante la Cuaresma, con el fin de combatir los siete pecados capitales, alcanzar las siete virtudes y restaurar los siete dones del Espíritu Santo comunicados a través del Bautismo.

En las referencias que se contienen en documentación inquisitorial a la recitación de los salmos penitenciales por parte de criptojudíos parecen aunarse las tradiciones cristiana y judía, pues si entre los cristianos se difundió desde el siglo XIII su recitación en las iglesias,

30 AHN, IT, leg. 133, n 21, fol. 17r. H. Beinart, Records, II, p. 344.

31 AHN, IT, leg. 184, nº 11, fol. 10r-v. H. Beinart, Records, III, p. 556.

32 La numeración de los salmos es distinta en el texto masorético hebreo y en la Septuaginta y la Vulgata, las versiones griega y latina de la Biblia, respectivamente, porque estos dos textos reúnen en uno solo los salmos 9 y 10 y 114 y 115 del texto masorético y, en cambio, dividen en dos los salmos 116 y 147 del texto masorético. 
no hay que perder de vista que la lectura de los salmos constituye un elemento fundamental en la liturgia comunitaria judía y en la oración privada de todo judío observante. En el proceso contra María González, mujer de Pedro de Villarreal, vecinos de Ciudad Real, el día 15 de julio de 1513 la acusada hizo una confirmación de la confesión que había hecho previamente, y declaró que un sábado se reunieron varios conversos en la casa de Fernando de Molina con motivo del desposorio de su hija Inés,

e la de Lorenço Franco leýa en un libro los Salmos Penitençiales, e que dezía la de Lorenço Franco que heran Salmos Penitençiales, e que este testigo no sabe leer. Fue preguntado sy oyó este testigo lo que rezavan. Dixo que le oyó decir: "Gloria sea al Padre, gloria sea al Fijo, gloria al Espíritu Santo ${ }^{33 " .}$

Es evidente que la recitación del Gloria trinitario no guarda ninguna relación con la lectura de los salmos. Pero lo que resulta ciertamente interesante es que en la reunión sabatina de los criptojudíos se recitaran los salmos penitenciales, quizá por influencia de la liturgia cristiana. Más explícita es, no obstante, la confesión que el día 28 de noviembre de 1503 hizo ante los inquisidores Luis Fernández, vecino de Ciudad Real, quien reconoció haber realizado algunas prácticas de la religión judía, por honra y observancia de la Ley de Moisés, y que "ansymesmo rezaba los syete salmos penitençiales en ebrayco. E ansymesmo digo mi culpa, que rezé los maytines del çeliah"34".

En esta declaración resulta especialmente relevante el hecho de que el acusado reconozca haber rezado los salmos penitenciales en hebreo, lo que sería interpretado por los inquisidores como una prueba inequívoca de judaísmo. Pero, además, confiesa haber rezado los selihot, unos poemas hebreos de carácter también penitencial ${ }^{35}$. En definitiva, Luis Fernández atendía a la costumbre cristiana de recitar los salmos penitenciales, pero judaizándola, de forma que los leía en hebreo y acompañaba su lectura con la de selihot.

Por último, resultan sorprendentes las referencias a "confesores de los confesos" que se contienen en el proceso inquisitorial promovido en los años 1484 y 1485 contra Juan González Escogido, un judeoconverso vecino de Ciudad Real. En su declaración del día 25 de octubre de 1484, Antón González, vecino de Ciudad Real, afirmó "que puede aber veynte e cinco años, poco más o menos, que este testigo oyó decir que Juan Escogido e el Podrido (Gonzalo Alonso Podrido), vecinos desta çibdad, eran los confesores de los confesos, e que asý era pública boz y fama en aquel tiempo en esta çibdad ${ }^{36 " . ~}$

Otros varios testigos del procurador fiscal se refieren a Juan González Escogido como "rabí de los confesos" y "confesor de los confesos"; así, Inés de Aguilera, mujer de Gonzalo de Guzmán, declaró que hacía cerca de veinte años había sido vecina de Juan González Escogido "e que oyó dezir muchas veçes que era rabí e confesor de los confesos ${ }^{37 "}$ ".

Es ciertamente enigmática esta figura de "rabí y confesor" de los conversos, porque si era muy frecuente que algún individuo de la comunidad criptojudía, más o menos instruido en la Ley judía, asumiera las funciones de rabí y de tutor espiritual del colectivo, resulta

33 AHN, IT, leg. 154, no 37, fol. 37v. H. Beinart, Records, II, pp. 296-297.

34 AHN, IT, leg. 147, nº 2, fol. 3r. H. Beinart, Records, II, pp. 136-137.

35 Los selihot (= perdones) son unas poesías que los judíos recitaban en los días de penitencia, principalmente en las sinagogas aunque también de forma privada. Son días especiales de penitencia en el calendario judío los diez días que van desde la fiesta de Año Nuevo (Tish a be av) hasta el día de Yom Kipur, es decir del 1 al 10 del mes de tishri.

36 AHN, IT, leg. 154, no 13, fol. 4v. H. Beinart, Records, I, p. 498.

37 Ibídem, p. 499. 
insólito que entre sus funciones tuviera la de confesar, algo propio del cristianismo y totalmente ajeno al judaísmo ${ }^{38}$. Pero alguna referencia documental despeja las dudas que pudieran plantearse en torno al sentido real de la palabra "confesor"; así, Alonso de Torres, el "mozo", afirmó que oyó decir a su padre, el licenciado Fernando de Córdoba, que "todos los conversos desta çibdad vivían como judíos y que los confesava Juan Escogido ${ }^{39 " . ~}$

Parece fuera de toda duda que Juan González Escogido unía a las funciones propias de los rabíes la de confesar, es decir la de escuchar y perdonar los pecados de los conversos, algo ciertamente sorprendente por las razones ya expuestas, de lo que no conozco otros casos similares en el mundo de los criptojudíos, y que, en mi opinión, constituye una evidencia de sincretismo cristiano-judío.

\section{RASGOS DE SINCRETISMO EN LAS MANIFESTACIONES MESIÁNICAS Y APOCALÍPTICAS DE LOS JUDEOCONVERSOS CASTELLANOS EN EL TRÁNSITO DE LA EDAD MEDIA A LA MODERNA}

A lo largo de la Edad Media, las comunidades hispano-hebreas experimentaron fenómenos mesiánicos muy similares a los de las comunidades judías diseminadas por la cuenca mediterránea, alcanzando sus más altas cotas en los años inmediatamente anteriores y posteriores a la expulsión de $1492^{40}$. Tras la desaparición del judaísmo de los reinos hispanos, los círculos de judaizantes se esforzaron por preservar y poner en práctica de forma oculta los principales ritos de la religión judía, con el propósito de seguir formando parte de la comunidad de los elegidos del pueblo de Israel; por ello, el mesianismo ocupó también un lugar fundamental en la mentalidad criptojudía ${ }^{41}$.

Uno de los principales movimientos mesiánicos es el que se propagó entre 1499 y 1502 por varias comunidades criptojudías de la Meseta sur castellana. Pese a que, en general, los profetas y profetisas eran personas con una escasa formación religiosa e intelectual, su mensaje cautivó a sus convecinos judeoconversos, dispuestos a seguir ciegamente sus indicaciones. El foco originario de este movimiento profético parece hallarse en las predicaciones del bachiller cordobés Alonso de Córdoba Membreque quien, ante más de un centenar de judeoconversos, predicaba que en marzo de 1500 se produciría la venida del profeta Elías, el precursor del Mesías ${ }^{42}$. En los procesos inquisitoriales incoados a varios seguidores de Alonso de Córdoba se describen las prácticas rituales que celebraban: un oficio religioso a medio camino entre un oficio judío sinagogal y una misa, y unas procesiones de hombres y mujeres vestidos de blanco, descalzos y con velas encendidas.

38 Si en el judaísmo primitivo la expiación de los pecados se conseguía mediante el sacrificio cúltico, en el judaísmo rabínico es la disposición interna de la persona la que permite repararlos, mediante la oración, la penitencia, la práctica de virtudes como la humildad, la generosidad o la beneficencia, o la aceptación resignada del sufrimiento. J. Maier y P. Schäfer, Diccionario del judaísmo, p. 153, voz "expiación".

39 Ibídem, p. 501.

40 Para una mayor profundización en estas cuestiones remito a mi trabajo titulado "La esperanza mesiánica en el judaísmo hispano medieval", Estudios de Historia de España, VIII (Buenos Aires, 2006), pp. 11-57, y a la bibliografía citada en el mismo.

41 Véase J. Edwards, "Elijah and the Inquisition: Messianic Profhecy among Conversos in Spain, C. 1500", en Nottingham Medieval Studies, 28 (Nottingham University, 1984), pp. 79-94.

$42 \mathrm{H}$. Beinart estudió estas predicaciones en su trabajo titulado "A Prophesyng Movement in Cordova in 1499-1502" (en hebreo), citado con anterioridad. La información se completa con la que ofrecen algunos procesos inquisitoriales incoados a varios conversos cordobeses que participaron en las reuniones presididas por el bachiller, y entre los que tiene un especial interés el incoado al mercader Juan de Córdoba Membreque, que fue transcrito por R. Gracia Boix, Colección de documentos para la historia de la Inquisición de Córdoba, doc. V, pp. 31-79. 
Este movimiento mesiánico cordobés está estrechamente relacionado con otros que tuvieron por escenario diversas localidades de las actuales provincias de Ciudad Real y Badajoz $^{43}$. El más importante de todos ellos es el protagonizado por una joven de quince años de edad llamada Inés Esteban, "la moza de Herrera", que residía en la localidad pacense de Herrera del Duque ${ }^{44}$. Sus predicaciones generaron una gran expectativa entre los conversos de toda la comarca, y aún de más lejos. Inés narraba su ascenso milagroso al cielo de la mano de su difunta madre, de un joven que había muerto hacía poco tiempo y de un ángel, quien le anunció que en el año 1500 vendría el profeta Elías; allí pudo contemplar el Purgatorio y las almas glorificadas de los conversos que habían sufrido la hoguera. En el proceso que fue incoado a Inés, el fiscal acusó a su padre y a un tío de ser los inductores de sus narraciones fantásticas.

Otro de los movimientos mesiánicos tuvo lugar en la localidad de Chillón, al suroeste de la provincia de Ciudad Real. Su protagonista fue también una joven, María Gómez, cuyas profecías son muy parecidas a las de Alonso de Córdoba e Inés Esteban. Asimismo hay referencias a otro profeta de la misma comarca, un cardador llamado Gómez, que era vecino de Almodóvar del Campo, localidad muy próxima a Puertollano.

Pese a que se trata de manifestaciones populares de profetismo y mesianismo judío, en ellas es posible descubrir ciertos rasgos de sincretismo cristiano-judío, que son también señales evidentes del proceso de aculturación al que, como todo grupo minoritario, estaban sujetos los criptojudíos castellanos de fines de la Edad Media y comienzos de la Moderna.

En los procesos inquisitoriales que fueron incoados a numerosos conversos seguidores de las profecías de Inés Esteban y María Gómez se recogen abundantes testimonios relativos a las visiones y a los "viajes celestes" de las profetisas. Es especialmente interesante, por la multiplicidad de detalles que ofrece, la confesión que hizo ante los inquisidores Juan de Segovia, vecino de la collación toledana de San Nicolás y seguidor de Inés Esteban:

Digo mi culpa, reverendos señores, que puede aver catorze meses, poco más o menos tienpo, que fuy desta çibdad para Ferrera a conprar çiertos cordovanes, como otras vezes solía, e llegando çerca de la villa, a las tenerías, fallé a un Lope Donoso, çapatero, veçino de la dicha villa, e me dixo: "Una maravilla a aconteçido esta noche pasada, que la fija de Juan Estevan ha sobido al çielo, que la llevó un ángel, y allá vio los que estavan en pena y en gloria", y otras cosas, las quales me dixo que muy más largamente me las dirían allá en la villa. Y vençido de lo quel susodicho me avía dicho, procuré de saber la verdad de aquello cómo pasava y qué cosa hera, y fueme a Juan Estevan, padre de la dicha moça, y dixe lo que el susodicho me avía dicho y que su fija subía al çielo, que me dixese la verdad y cómo

$43 \mathrm{H}$. Beinart ha estudiado los más importantes movimientos mesiánicos que tuvieron lugar entre los judaizantes hispanos en el momento de tránsito de la Edad Media a la Moderna, y los ha dado a conocer en diversos artículos publicados en hebreo: "Conversos of Chillón and Siruela and the Prophecies of Mari Gómez and Inés, the Daughter of Juan Esteban" (en hebreo), en Zion, 48 (1983), pp. 241-272; "Anuse Alia (Halia) u-tenu'atah sel ha-nebi'ah Inés" (= "Los judeoconversos de Alía y el movimiento de la profetisa Inés"), en Zion, 53/I (1988), pp. 13-52; y "Tenu'at ha-nebi ah Inés be-Puebla de Alcocer u-be Talarrubias we-anusehen sel ayyarot elleh", en Tarbiz, 51 (1982), pp. 633-658.

44 Además de los artículos de $\mathrm{H}$. Beinart citados en la nota anterior, son fundamentales para el estudio del movimiento profético liderado por Inés Esteban varios trabajos de la profesora M. P. Rábade Obradó: "Herejía y utopía en la Castilla de los Reyes Católicos. Los conversos y la esperanza mesiánica", en J. Contreras Contreras, J. Alvar Ezquerra y J. I. Ruiz Rodríguez (Coords), Política y cultura en la época Moderna. (Cambios dinásticos, milenarismos, mesianismos y utopías), Universidad de Alcalá, 2004, pp. 535-544, y "Dos voces femeninas en la Castilla del siglo XV: sueños y visiones de los criptojudíos", en M. Alvira Cabrer y J. Díaz Ibáñez, Medievo utópico: sueños, ideales y utopías en el mundo imaginario medieval, Madrid, Sílex ediciones, 2011, pp. 53-66. 
pasava. Y el dicho Juan Estevan me dixo que hera verdad como me lo avían dicho, y que para ser más çierto dello, que negoçiase mis negoçios a que yva, y yo faré que os lo cuente la dicha mi fija muy por estenso y claro cómo pasa. Y asý, andando negoçiando mis negoçios en la plaça, el dicho Juan Estevan me dixo que fuésemos a su casa a fablar a la dicha su fija, y pregunté a la dicha moça que me contase qué es lo que le aconteçía y cómo sobía al çielo, y ella se enbaraçó un poco, y el dicho su padre le dixo: "Fija, dile toda la verdad, como pasa". Y entonçes la dicha moça me dixo cómo su madre, que hera ya defunta, venía a ella y la tomava de la mano y la dezýa que no temiese, porque la voluntad de Dios harea que subiese al çielo y viese los secretos y viese cosas maravillosas. $Y$ asymismo la tomava de la otra mano otro moço que hera falleçido pocos días avíe, y el ángel que les yva guiando. Y asý dizýe que la sobían al çielo, donde veýa el Pulgatorio y las ánimas que en él estavan penando, y ansymismo en otro cabo cómo estavan en unas syllas de oro otros en gloria. $Y$ asymismo me dixo questando ansý, que ençima de su cabeça, en otra estançia más alta, le paresçía que avía mucho mormollo, y preguntó al ángel que qué hera aquello que allí sonava ençima, y el ángel le dixo: "Amiga de Dios, aquellos que suenan allý arriva son los que han quemado acá en la tierra, que están allý en gloria", y ansymismo que víe ángeles de tres maneras, y otras cosas que me dixo que non tengo en la memoria. $Y$ ansý quedé con tanta confusyón y turvaçión que ni sabía determinarme quál sería la verdad o qué devía de creer. Y entre las otras cosas que la susodicha moça me dixo, me avía dicho que avía pedido al ángel que le diesen una señal por donde fuese creýda lo que dixese, y quel ángel le respondió quél le trayríe una carta del Señor. Y yo, como estava encrédulo y non chica turvaçión, díxele al dicho Juan Estevan que me fizyese saber quando aquella carta truxesen a la dicha su fija, o qualquier otra cosa que de nuevo se ofreçiese. $Y$ venido a mi casa, a esta dicha çibdad, yo dixe y conté todo lo susodicho, como avía pasado, a mi muger. Y ansý turvados, y ansý la dicha mi muger e yo non sabiendo nos determinar quál fuese la verdad y lo que devíamos creer, dende en çiertos días vino a esta çibdad Luys Guantero, veçino de la dicha villa de Herrera, de quien avía conprado çierto cordován, que me avía fyado, el qual aposenté en mi casa. Y fablando con el dicho Luys Guantero, me dixo cómo las dichas cosas que la moça me dixo y su padre cada día yvan más creçiendo, porque cada semana la sobían una vez al çielo. Yo le pregunté sy avía traýdo alguna señal del çielo. Él me dixo que tres; la una hera una espiga tan grande, y la otra una azeytuna, y la otra una cartyca, y en esto non dudase más que en Dios, y que en esto non creyese que no se podía salvar, ques guardar la ley y creer la ley de Moysén, y que hera razón de ayunar, porque en aquella tierra de Herrera todos lo fazýan asý, fasta las criaturas de syete o de ocho años las fazýen ayunar, y que no curavan nadie de fazyenda, porque lo tenían por muy çierto, y ansý los que tenían davan a los que non tenían con aquel esperança de ser llevados aquellas tierras de promisyón, y cómo Dios tenía fecha una çibdad en el çielo muy eçelente, que avía de ser trasladada en la tierra, donde todos los conversos avíen de morar y bivir en grande abundançia, syn nesçesydad ninguna. Y esto y otras muchas cosas quel dicho Luys Guantero me dixo. $Y$ vençido de sus razones, creý lo susodicho y ayuné algunos días a modo judayco ${ }^{45}$.

También María Gómez de Chillón experimentaba "viajes celestes", como se expresa en la declaración de Elvira Ruiz, vecina de Herrera del Duque, ante los inquisidores:

E dende ocho o diez días, poco más o menos, vino la tintorera, que se llama Elvira Martínez, del pueblo de Chillón, e contóme cómmo le avían dicho que en Chillón avía venido a una moça que se llama María Gómez, que era ya casada, su madre, que era ya falesçida, e que le avía dicho que era elegida del Señor e que la llevarían al çielo e los ángeles vernían por ella a donde verrá cosas maravillosas. E asý fue que fue llevada al çielo, e que dezía la dicha María Gómez que estavan aparejadas muchas buenas andanças para los conversos

45 AHN, IT, leg. 184, nº 6, fol. 4r-v. 
que ayunasen e guardasen el sábado e fiziesen otras çerimonias de la ley de Moysén, porque todos avían de ser llevados aquellas tierras santas de promisyón, e los que non ayunasen y fiziesen las otras cosas que se quedarían al pie del puerto. E con estas cosas tantas commo me dixo, trastorné mi coraçón y voluntad. E vino otra vez la dicha tintorera, porquel tinte era çerca de donde yo morava, e díxome cómmo la hija de Juan Estevan sobía al çielo e dezía otras muchas cosas conformes a la dicha muger de Chillón ${ }^{46}$.

Asimismo se conocen por otros procesos inquisitoriales las experiencias místicas de Gómez, vecino de Almodóvar del Campo. En el proceso incoado a Alonso de Villarreal, vecino de la misma localidad, se contiene la declaración que el día 23 de abril de 1501 hizo ante los inquisidores Diego de Marchena, cuñado de Gómez y vecino de Córdoba:

Dixo que podía aver un año, poco más o menos, questando este testigo en Almodóvar del Canpo e morando allí, estando casado con una hermana del dicho Gómez, profeta falso, el dicho Gómez morava en casa deste dicho testigo, e vio este testigo cómo por espaçio de dos o tres meses el dicho Gómez se amorteçía dos bezes cada semana, jueves en la noche e domingo en la noche, e que des que despertava dezía que benía de tierra de promisión e que subía al çielo e que veýa los ángeles e ellos le tomavan e lo subían e lo dezían e lo llevavan a paraýso, e que lo llevavan adonde estavan syete mill moços que estavan para casar con las moças que avían de yr de acá, e que avía asymismo seys moças que se avían de casar con seys profetas que avían de yr de acá, e que donde estavan aquellos moços estava una casa de oraçión para que hiziesen oraçión los que de acá fuesen ${ }^{47}$.

La "ascensión" o "viaje celeste", como se denomina a la subida milagrosa de una persona al cielo, tiene una larga tradición en el judaísmo. Si las experiencias de ascensión del alma al cielo, normalmente en estado de éxtasis, alcanzaron una gran difusión en el judaísmo por influencia del neoplatonismo y dejaron una huella profunda en la religiosidad popular, las experiencias de ascensión en persona están estrechamente relacionadas con especulaciones esotéricas, y tuvieron su principal difusión desde los tiempos talmúdicos. Estos "viajes celestes" permitían la contemplación de la majestad divina y la comunicación de conocimientos y revelaciones ${ }^{48}$. Las especulaciones que concebían el cielo como la morada de Dios y los ángeles tenían un origen bíblico, pero fue en la literatura postbíblica cuando conocieron su mayor desarrollo, llegando a constituir un tema recurrente en la apocalíptica y el esoterismo judío. Así, quedó configurado en la literatura apocalíptica judía un sistema de siete cielos, que desde entonces constituyó el objetivo principal de interés de las visiones y de los "viajes celestes" de místicos y visionarios populares ${ }^{49}$. Del mismo modo, los sueños son considerados también en la Biblia un medio especial de revelación divina, como predicciones o avisos de Dios, de forma que son numerosas las referencias bíblicas a sueños y a su interpretación, lo que tuvo posteriormente un considerable desarrollo en la literatura místico-esotérica y en la religiosidad popular judía de tiempos medievales ${ }^{50}$. Por lo tanto, las referencias a "viajes celestes", visiones, apariciones y sueños que se contienen en los procesos inquisitoriales promovidos contra numerosos judeoconversos castellanos

46 AHN, IT, leg. 181, n 13, fol. 4r. F. Baer, Die Juden im Christlichen Spanien. I/2. Kastilien/Inquisitionakten, Berlín, 1936, pp. 533-535.

47 AHN, IT, leg. 188, no 5, fol. 11r.

48 J. Maier y P. Schäfer, Diccionario del judaísmo, pp. 49-50, voz "ascensión/ascensiones".

49 Ibídem, pp. 94 y 411, voces "cielo" y "visiones".

50 Ibídem, p. 382, voz "sueños/interpretación de los sueños", y S. Ausejo, Diccionario de la Biblia, Barcelona, Editorial Herder, 1964, pp. 1886-1887, voz "sueños". 
seguidores de las profetisas Inés Esteban y María Gómez se encuentran dentro de la tradición judía. Pero en los relatos que se hacen de estas experiencias místicas es posible detectar rasgos que no son propios del judaísmo y que serían el resultado de la influencia que la cultura religiosa y la mentalidad cristiana ejercían sobre el colectivo criptojudío, pese a su firme voluntad de resistencia frente a los inevitables influjos del cristianismo.

La alusión que se hace en la narración del "viaje celeste" de Inés Esteban al ángel que la guía en su ascensión y su recorrido por el cielo, así como el relato de las distintas estancias celestiales que allí pudo ver, encajan en la tradición judía. Sin embargo, la idea del cielo como un espacio físico que trasciende del final de los pasajes de la confesión de Juan de Segovia ${ }^{51}$ y de la declaración de Diego de Marchena ${ }^{52}$ incluidos más arriba encajan más en la concepción cristiana del cielo que en la judía. Y sobre todo, como ya he señalado anteriormente, la mención del Purgatorio es algo absolutamente ajeno al judaísmo, y es un rasgo evidente de sincretismo cristiano-judío; aunque se trata de una cuestión sumamente compleja, y que requeriría de un estudio específico, considero que esta visión del Purgatorio pudiera estar inspirada en el viaje celeste relatado por Dante Alighieri en la Divina Comedia, una obra que conoció una extraordinaria difusión en la Baja Edad Media, no solo en Italia sino en todo el Occidente europeo; como es bien sabido, una de las tres estancias visitadas por Dante en su viaje celestial es el Purgatorio (las otras dos son el Infierno y el Paraíso). Y quizá también puedan tener su origen en la Divina Comedia las frecuentes alusiones en las profecías mesiánicas y apocalípticas de los judeoconversos castellanos a los ríos que habrían de cruzar los conversos en su camino hacia las tierras de promisión (se habla de ríos de agua, de leche, de miel o de sangre), en los que se lavarían y se vestirían una camisa blanca para acceder purificados a las tierras de promisión ${ }^{53}$. Esta idea quizá se corresponda con el baño de Dante en los ríos Leteo y Eunoe, para acceder limpio de pecado al Paraíso ${ }^{54}$. Por el contrario, en la referencia a que los conversos cruzarían un río de leche y otro de miel antes de acceder a las tierras de promisión veo una evocación a los múltiples relatos bíblicos sobre Canaán, la Tierra Prometida, como una tierra sobreabundante en leche y miel. Uno de los testigos que declararon en el proceso inquisitorial contra Juan de Córdoba Membreque afirmó que el procesado decía en sus predicaciones que

en el camino por donde fuesen a las dichas tierras de promisión avían de pasar tres ríos, uno de leche y otro de miel e otro de sangre, e que en el dicho río de la leche se avían de bañar todos los confesos, viejos et moços, e todos los que asý en el dicho río se bañasen avían de quedar de hedad cada uno de veynte et cinco años ${ }^{55}$.

51 [...] cómo Dios tenía fecha una çibdad en el çielo muy eçelente, que avía de ser trasladada en la tierra, donde todos los conversos avíen de morar y bivir en grande abundançia, syn nesçesydad ninguna (AHN, IT, leg. 184, $\mathrm{n}^{\circ} 6$, fol. $4 \mathrm{v}$ ).

52 [...] subía al çielo e que veýa los ángeles e ellos le tomavan e lo subían e lo dezían e lo llevavan a paraýso, e que lo llevavan adonde estavan syete mill moços que estavan para casar con las moças que avían de yr de acá, e que avía asymismo seys moças que se avían de casar con seys profetas que avían de yr de acá, e que donde estavan aquellos moços estava una casa de oraçión para que hiziesen oraçión los que de acá fuesen (AHN, IT, leg. 188, $n^{\circ} 5$, fol. 11r).

53 El color blanco representa en la Biblia, simbólicamente, la alegría, la inocencia y la gloria celestial.

54 El Leteo, o río del olvido, es uno de los ríos que, según la mitología clásica, atravesaban el Hades, es decir la tierra de los muertos, desembocando en la laguna Estigia. Todo aquel que bebía o se bañaba en sus aguas perdía de forma irremediable la memoria. Junto a él estaba el río Mnemosine o río de la memoria, que permitía obtener un conocimiento infinito. Dante toma este tema de la mitología clásica y otorga al baño en el río Leteo la capacidad de hacer olvidar las culpas cometidas, borrando incluso el mismo recuerdo del pecado, y al baño en el río Eunoe la capacidad de hacer reavivar el recuerdo de las buenas acciones practicadas.

55 AHN, Inquisición, leg. 4.724, doc. 2, fol. 21v. R. Gracia Boix, Colección de documentos para la historia de 
Asimismo es posible detectar ciertas similitudes de algunos pasajes de las narraciones de los "viajes celestes" de las profetisas criptojudías con el Apocalipsis de san Juan, así como con relatos cristianos contemporáneos sobre apariciones de la Virgen. De este modo, la visión que ofrece Inés Esteban de las estancias del cielo que visita recuerdan mucho a la descripción que se hace del cielo en el capítulo IV del libro del Apocalipsis, cuando se describe el trono de Dios, con los 24 ancianos que lo adoran, sentados en 24 sillas "revestidos de ropas blancas y con coronas de oro en sus cabezas". Y la referencia de Inés Esteban a los conversos quemados por la Inquisición recuerda también mucho a la visión del Apocalipsis (VI, 9) cuando, tras abrir el quinto sello, san Juan observa debajo o al pie del altar las almas de los que habían sufrido el martirio por la palabra de Dios, a los que se hizo entrega después de un vestido blanco (VI, 11). En el capítulo VII se hace nuevamente referencia a los mártires de la palabra de Dios como una enorme muchedumbre de personas revestidas de vestidos blancos, que venían de una gran tribulación, y que habían blanqueado y purificado sus ropajes en la sangre del Cordero.

Del mismo modo, en el interesante estudio de William A. Christian sobre apariciones en Castilla y Cataluña en los siglos XIV al XVI ${ }^{56}$ se contienen diversos relatos en los que es posible detectar algunos detalles muy similares a los que aparecen en las narraciones de las predicaciones y experiencias místicas de los criptojudíos castellanos. Veamos algunos de ellos.

En casi todos los relatos cristianos de visiones y apariciones se hace referencia a la solicitud por el vidente de una señal que sirviera como prueba de la veracidad de su visión. La señal que recibía el vidente podía ser un signo corporal (los cuatro dedos de una mano pegados y el pulgar fijado sobre ellos en forma de cruz o los labios pegados) o la curación de alguna dolencia o defecto físico. De modo idéntico, Inés Esteban solicitó al ángel que la guió al cielo una señal para ser creída, recibiendo una espiga y una aceituna de tamaño fuera de lo normal y una "cartica", es decir un escrito breve con algún mensaje divino.

Por otra parte, en las visiones y apariciones cristianas se hace referencia en ocasiones a la presencia de algún familiar o conocido fallecido recientemente ${ }^{57}$, algo que se observa también en las visiones de los criptojudíos, como sucede con las apariciones de la madre de Inés Esteban, del joven vecino de Herrera del Duque y de la madre de María Gómez, a las que se hace referencia en los pasajes incluidos anteriormente, o con la del suegro de Luis Alonso, un vecino de Herrera del Duque. En el proceso promovido contra Mayor González se contiene la declaración hecha el 10 de diciembre de 1500 por la procesada, en la que se dice que Luis Alonso le había dicho

questando en Chillón, una noche avía venido a él en sueños una cosa, que no sabía qué se era, que le paresçía a él que le dezía que en el canpo le paresçería. Y asý, yendo un día por el canpo, le paresçió un su suegro, quera muerto días avía, y le dixo muchas cosas maravillosas questavan aparejadas para los conversos en las tierras de promisión, mas que para yr a ellas que convenía que se bolbiesen al Señor, y ayunasen ayunos de judíos, y creyesen la ley de Muysén, y guardasen los sábados y fiziesen otras cosas de la dicha ley ${ }^{58}$.

Del mismo modo, en relación con las ascensiones al cielo de Inés Esteban es particularmente interesante la declaración que hizo un joven llamado Pedro, que era hijo

la Inquisición de Córdoba, p. 56.

56 W. A. Christian, Jr., Apariciones en Castilla y Cataluña (siglos XIV-XVI), Madrid, Nerea, 1990.

57 Ibídem, p. 226.

58 AHN, Inquisición, leg. 155, nº 6, fol. 4r. 
de Juan Díaz, ya difunto, y de Beatriz González, judeoconversos vecinos de la localidad cacereña de Alía. Ante los inquisidores manifestó que había acudido con su tío Lope Alonso a Herrera del Duque, y que tenía mucho interés en hablar con Inés, probablemente con la intención de preguntarle si en su viaje al cielo había visto a su padre; consiguió hablar con el padre de Inés, Juan Esteban,

que me llamó e díxome: "Estas cosas non son de dezir a mochachos, mas yo pregunté a mi fija e dixo que tu padre está en los çielos", e non me dexó entrar a ver la moça. E después quél se fue, yo entré e vila donde estava, e ella me dixo: "Primo, en ora buena vengáys. A vuestro padre vi en los çielos, e se vos encomienda a vos e a vuestra madre". E yo me bolví e lo dixe a mi madre esto que me avía pasado, e ella me respondió: "Plázeme que lo creerás". E esto hera e pasó un jueves, porque dezían que los jueves en las noches subía la dicha moça al çielo, e yo vine el viernes a mi madre ${ }^{59}$.

Es sugestiva la idea de que Juan Díaz se encomendaba a las oraciones de su hijo y de su esposa porque, aunque en el judaísmo se acostumbra la oración por los difuntos (qadish), en mi opinión, esta solicitud tiene más que ver con la recomendación cristiana de la oración por las almas y, particularmente, la veo como una manifestación de sincretismo cristiano-judío.

Asimismo hay semejanzas entre los relatos de las visiones y apariciones cristianas y las de los criptojudíos en lo que se refiere al tiempo y al lugar en el que se materializaban. De este modo, las visiones de la Virgen y los santos tenían lugar, normalmente, durante la noche o al alba, estando solo el vidente en un sitio apartado y sin presencia de testigos. Y lo mismo sucede en el caso de los criptojudíos, como se deduce del relato de la visión que Luis Alonso tuvo de su suegro una noche, en sueños, y de su aparición en persona en el campo, transcrito más arriba, o de la narración de las ascensiones al cielo de Inés Esteban, María Gómez y Gómez de Almodóvar, que también se producían durante la noche estando en casa. Sirva de ejemplo la declaración que el día 31 de julio de 1501 hizo ante los inquisidores Gonzalo Fernández, vecino de Herrera del Duque, en el proceso promovido contra Mari García, vecina de esta misma localidad; según el declarante, Gonzalo Bechancho, vecino también de Herrera, decía que Inés Esteban subía al cielo, y que lo sabía porque

la prové una noche que me acosté con su padre por ver sy era verdad que subía al çielo, e que me levanté de la cama después de todos dormidos e la atenté la cara y la hallé más fría que la nieve, e la tomé el pulso e non le hallé pulso, e la atenté el cuerpo e las piernas por ver sy el spíritu era subido al çielo, e hallela más que la nieve, que sy no fue en el tobillo e en otro cabo non le hallé pulso ${ }^{60}$.

Y también Gómez de Almodóvar se trasponía (se amorteçía) durante la noche dos días a la semana, los jueves y los domingos, en la casa de su hermana Beatriz González, y eran bastantes los conversos que acudían allí para oír las cosas que decía cuando se levantava del amorteçimiento ${ }^{61}$.

Los relatos de las apariciones de la Virgen suelen hacer referencia a una luz intensa o a un gran resplandor y claridad, algo que también sucede en las apariciones que experimentaban los criptojudíos. En la declaración que el día 21 de mayo de 1500 hizo Inés Esteban ante los inquisidores expuso que hacía algún tiempo

59 AHN, Inquisición, leg. 174, nº 3, fol. 3r.

60 AHN, IT, leg. 150, no 11 , fol. 5V.

$61 \mathrm{AHN}, \mathrm{IT}$, leg. 188, no 5, fols. $6 r$ y v, 10v y 11 r. 
çerca de Navidad primera que pasó, vino a ella una claridad, que antes otras vezes dixo avía venido, e este testigo le dixo que a qué era su venida, pues que tantas vezes venía. E respondióle e dixo que venía a le dezir que avía de venir Elías en el año de quinientos, e que para esto cunplía que hizyesen ayunos e diesen limosnas e hizyesen el más bien que pudiesen. E este testigo le preguntó quién era este Elías e quién avía de venir, e díxole que avía de venir por mandamiento de Dios a predicar en el mundo, e que avían de salir los conversos e avían de yr a unas tierras. E le preguntó esta confesante en estas tierras qué avía, e díxole que avía poblaçiones e mantenimientos de pan e de frutas e de las cosas que cunplían. E luego desapareçió; e primero que se fuese le dixo que dixese esto que le avía dicho ${ }^{62}$.

También Beatriz, hija de Luis Alonso, vecina de Herrera, vio una claridad en su casa, como declaró ante los inquisidores: "Y asimismo, entrando una mañana en el palasçio en mi casa, paresçiome que vi una claridad, y díxelo a mi madre, y él nos dixo que era Abrahán, questava aposentado en nuestra casa ${ }^{63 "}$.

Si los cristianos veían en sus apariciones a la Virgen o a algún santo, los criptojudíos creían adivinar en las suyas a algún patriarca o profeta del antiguo Israel. Si Beatriz recibía la manifestación de Abraham a través de una claridad, en otras ocasiones les parecía ver a Moisés; como expone Diego García, vecino de Siruela (Badajoz), Rodrigo Cordón, vecino de la misma localidad, le había dicho que "avían visto en la luna un onbre con una vara de oro en la mano, e pensaron que era señal. E este testigo le preguntó qué señal pensaban que era. E el dicho Rodrigo le dixo que pensaron que era Moysén ${ }^{64 " .}$

Las referencias a ángeles son frecuentes en las narraciones de los viajes celestes de Inés Esteban y María Gómez y en las visiones que experimentaban otros conversos. Como sucedía en las apariciones y visiones cristianas, los ángeles se muestran vestidos de blanco y resplandecientes; Diego García, vecino de Herrera del Duque, afirmaba que Rodrigo Cordón le había contado las noticias que corrían por su barrio: "Sabed que viene un ángel a casa de Diego, ollero, vuestro vezino, muy relumbrante, commo de oro, y se pone sobre la cama dellos, e no dize nada nin les habla ${ }^{65 " .}$

Las vestiduras blancas son, en efecto, otro elemento común a las apariciones y visiones cristianas y de los criptojudíos. De este modo se quiere lanzar un mensaje inequívoco de que las personas así vestidas procedían del cielo o del reino de ultratumba. De color blanco resplandeciente son los vestidos que llevan en sus apariciones la Virgen, los santos y los ángeles y arcángeles, así como los hombres y mujeres que procesionan con candelas encendidas en varias de las apariciones y visiones cristianas de los siglos XIV al XVI recogidas por William A. Christian. Y exactamente lo mismo sucede en los relatos apocalípticos de las peregrinaciones que los criptojudíos emprenderían a las tierras de promisión tras la venida del profeta Elías para rescatarlos, ya que para entrar en las tierras de promisión deberían vestir una camisa blanca, y en las procesiones de los criptojudíos cordobeses que seguían a las predicaciones del bachiller Alonso de Córdoba Membreque, y que recuerdan mucho a las procesiones de las apariciones y visiones cristianas ${ }^{66}$ :

et les avía de hazer vestir camisas blancas amogiladas, syn tener en ellas color ninguno, salvo todo blanco, et unos calçones calçados blancos, et sacadas candelas blancas

62 AHN, IT, leg. 147, no 13, fol. 9r-v.

63 AHN, IT, leg. 137, no 9, fol. 3r.

64 AHN, IT, leg. 139, no 15, fol. 5v.

65 Idem.

66 Véase W.A. Christian, Jr., Apariciones en Castilla y Cataluña (siglos XIV-XVI), pp. 58 y 60-61. 
ençendidas en las manos, et que los avía de sacar por las çibdades e villas e logares donde estoviesen los conversos en proçesión a vista de todo el mundo, et que en mitad de todas las çibdades e villas e logares avían de predicar al dicho Elías, de tal manera que se convertiese a todos los christianos viejos a la ley de los judíos ${ }^{67}$.

\section{A MODO DE CONCLUSIÓN}

En las páginas precedentes se han ofrecido diversos ejemplos documentados de sincretismo cristiano-judío en las creencias y prácticas religiosas de los judeoconversos castellanos en el momento de tránsito de la Edad Media a la Moderna. Los teólogos cristianos y la Inquisición condenaron de forma terminante estas manifestaciones sincréticas, por el temor a que el cristianismo pudiera verse contaminado con elementos propios del judaísmo. Pero, desde el lado de los criptojudíos, se trata de un proceso imparable, de forma que las expresiones y manifestaciones sincréticas fueron cada vez más frecuentes en la "religión" de los criptojudíos, como expresión de una realidad en la que el judaísmo comenzaba a ser un recuerdo demasiado lejano, una manifestación cada vez más cultural y folclórica que propiamente religiosa y, en la mayor parte de los casos, una decidida voluntad de alteridad frente a los cristianos y el cristianismo. Era el reflejo fiel de una realidad en la que, rotas las conexiones con el judaísmo oficial, la "religión" de los criptojudíos se diluía paulatinamente en el seno del cristianismo.

\section{BIBLIOGRAFÍA}

Ausejo, S., Diccionario de la Biblia, Barcelona, Editorial Herder, 1964.

Baer, F., Die Juden im Christlichen Spanien. I/2. Kastilien/Inquisitionakten, Berlín, 1936.

Beinart, H., Records of the Trials of the Spanish Inquisition in Ciudad Real, Jerusalem, The Israel National Academy of Sciences and Humanities, 1974-1985, 4 vols.

Beinart, H., "A Prophesyng Movement in Cordova in 1499-1502" (en hebreo), en I.F. Baer Memorial Volume, Zion, 44 (1979), pp. 190-200.

Beinart, H., "Tenu'at ha-nebi ah Inés be-Puebla de Alcocer u-be Talarrubias we-anusehen sel ayyarot elleh", en Tarbiz, 51 (1982), pp. 633-658.

Beinart, H., Los conversos ante el tribunal de la Inquisición, Barcelona, Riopiedras Ediciones, 1983.

Beinart, H., "Conversos of Chillón and Siruela and the Prophecies of Mari Gómez and Inés, the Daughter of Juan Esteban" (en hebreo), en Zion, 48 (1983), pp. 241-272.

Beinart, H., "Anuse Alia (Halia) u-tenu'atah sel ha-nebi'ah Inés" (= "Los judeoconversos de Alía y el movimiento de la profetisa Inés"), en Zion, 53/l (1988), pp. 13-52.

Bover, J. Ma, S. I., y Cantera Burgos, F., Sagrada Biblia. Versión crítica sobre los textos hebreo y griego, Madrid, Biblioteca de Autores Cristianos, 1961 (6ª ed.).

Carrete Parrondo, C., Fontes Iudaeorum Regni Castellae. II. El Tribunal de la Inquisición en el Obispado de Soria (1486-1502), Salamanca, Universidad Pontificia de SalamancaUniversidad de Granada, 1985.

Carrete Parrondo, C., Fontes iudaeorum Regni Castellae. III. Proceso inquisitorial contra los Arias Dávila segovianos: un enfrentamiento social entre judíos y conversos, Salamanca, Universidad Pontificia de Salamanca-Universidad de Granada, 1986.

Carrete Parrondo, C. y Fraile Conde, C., Fontes Iudaeorum Regni Castellae. IV. Los judeoconversos de Almazán. 1501-1505. Origen familiar de los Laínez, Salamanca, Universidad Pontificia de Salamanca-Universidad de Granada, 1987.

67 AHN, Inquisición, leg. 4.724, doc. 2, fol. 2r. R. Gracia Boix, Colección de documentos para la historia de la Inquisición de Córdoba, p. 33. 
Christian, W. A., Jr., Apariciones en Castilla y Cataluña (siglos XIV-XVI), Madrid, Nerea, 1990.

Edwards, J., "Elijah and the Inquisition: Messianic Profhecy among Conversos in Spain, C. 1500", en Nottingham Medieval Studies, 28 (Nottingham University, 1984), pp. 79-94.

Garrido Bonaño, M., O.S.B., Curso de Liturgia Romana, Madrid, Biblioteca de Autores Cristianos, 1961.

Gitlitz, D. M., Secreto y engaño. La religión de los criptojudíos, Salamanca, Junta de Castilla y León, 2003.

Gracia Boix, R., Colección de documentos para la historia de la Inquisición de Córdoba, Córdoba, Publicaciones del Monte de Piedad y Caja de Ahorros de Córdoba, 1982.

Le Goff, J., La naissance du Purgatoire, Paris, Gallimard, 1981.

Maier, J. y Schäfer, P., Diccionario del judaísmo, Estella, Editorial Verbo Divino, 1996.

Rábade Obradó, M. P., "Expresiones de la religiosidad cristiana en los procesos contra los judaizantes del tribunal de Ciudad Real/Toledo, 1483-1507", En la España Medieval, 13 (1990), pp. 303-330.

Rábade Obradó, M. P., "Religiosidad y práctica religiosa entre los conversos castellanos (1483-1507)", Boletín de la Real Academia de la Historia, tomo CXCIV, Cuaderno I (Enero-Abril, 1997), pp. 83-141.

Rábade Obradó, M. P., "La instrucción cristiana de los conversos en la Castilla del siglo XV", En la España Medieval, 22 (1999), pp. 369-393.

Rábade Obradó, M. P., "Herejía y utopía en la Castilla de los Reyes Católicos. Los conversos y la esperanza mesiánica", en Contreras Contreras, J., Alvar Ezquerra, J. y Ruiz Rodríguez, J. I. (coords.), Política y cultura en la época Moderna. (Cambios dinásticos, milenarismos, mesianismos y utopías), Universidad de Alcalá, 2004, pp. 535-544.

Rábade Obradó, M. P., "Dos voces femeninas en la Castilla del siglo XV: sueños y visiones de los criptojudíos", en Alvira Cabrer, M. y Díaz Ibáñez, J., Medievo utópico: sueños, ideales y utopías en el mundo imaginario medieval, Madrid, Sílex ediciones, 2011, pp. 53-66.

Scholem. G., The Messianic Idea in Judaism, New York, Schockem, 1971.

Trebolle Barrera, J., "Apocalipticismo y mesianismo en el mundo judío", en Mangas, J. y Montero, S., (Coords.), El Milenarismo. La percepción del tiempo en las culturas antiguas, Madrid, Editorial Complutense, 2001. 